\title{
Cycle Time Reduction in Injection Molding Process by Selection of Robust Cooling Channel Design
}

\author{
Muhammad Khan, ${ }^{1}$ S. Kamran Afaq, ${ }^{1}$ Nizar Ullah Khan, ${ }^{2}$ and Saboor Ahmad ${ }^{3}$ \\ ${ }^{1}$ Mechanical Engineering Department, HITEC University, Taxila, Pakistan \\ ${ }^{2}$ Department of Mechanical Engineering, Oakland University, Rochester, USA \\ ${ }^{3}$ SMME, NUST, Islamabad, Pakistan \\ Correspondence should be addressed to Muhammad Khan; muhammad.khan@hitecuni.edu.pk
}

Received 18 January 2014; Accepted 2 March 2014; Published 25 March 2014

Academic Editors: A. Z. Sahin and X. Yang

Copyright (C) 2014 Muhammad Khan et al. This is an open access article distributed under the Creative Commons Attribution License, which permits unrestricted use, distribution, and reproduction in any medium, provided the original work is properly cited.

Cycle time of a part in injection molding process is very important as the rate of production and the quality of the parts produced depend on it, whereas the cycle time of a part can be reduced by reducing the cooling time which can only be achieved by the uniform temperature distribution in the molded part which helps in quick dissipation of heat. Conformal cooling channel design is the solution to the problem which basically "conforms" to the shape of cavity in the molds. This paper describes the analytical study of cooling analysis of different types of cooling channel designs. The best cooling channel design is also selected on the basis of minimum time to reach ejection temperature, uniform temperature distribution, and minimum warpage of part. "Creo Elements/Pro 5.0" is used to model the case study, its molds, and the cooling circuit whereas analytical study is done using "Autodesk Moldflow Advisor 2013 (AMFA)."

\section{Introduction}

Injection molding is a major part of the plastic industry and is a huge business worldwide, consuming approximately $32 \mathrm{wt} \%$ of all plastic. It is in the second place to extrusion, which consumes approximately $36 \mathrm{wt} \%$ [1]. The injection molding process consists of melting of polymer and then its injection into the cavity in the molds. This molten material is ejected from the molds after reaching the cooling temperature. Thus, the main phases of the injection molding process are injection, packing, cooling, and part ejection. Among these, part cooling takes up 50 to 80 percent of the cycle time [2]. The amount of time in the injection and packing phases is low and cannot be reduced much further. However, because cooling time can be more than two-thirds of the molding cycle, a cooling time reduction will considerably increase the production rate as well as reduce costs [3]. But decreasing cooling time can result in excessive shrinkage and warpage in parts [4]. So there is a need of a cooling technique to reduce the cycle time without compromising on part quality.
In the cooling phase, heat transfers between the molten material inside the cavity and the cooling fluid (generally water) flowing through the cooling channels inside the mold, until ejection temperature is achieved and part is stable enough for demolding. Thus this rate of heat exchange is very important and directly related to the time taken by the cooling phase. So it is important to understand and optimize the cooling channel design to optimize the rate of heat transfer in an injection molding process. Proper design of the cooling channel is required for a faster cooling phase. Historically, the cooling channels have been created by drilling several straight holes (cooling channels) inside the mold core and cavity. Such type of cooling channels is called as "Conventional Cooling Channels (CCC)." However the cooling process in CCC is too long because of nonuniform cooling of part. If the part's temperature can be reduced more quickly and uniformly, it will shorten the cooling time without compromising on part quality because nearly uniform temperatures can be held in part by using conformal cooling [4]. In conformal cooling channel, the shape of 


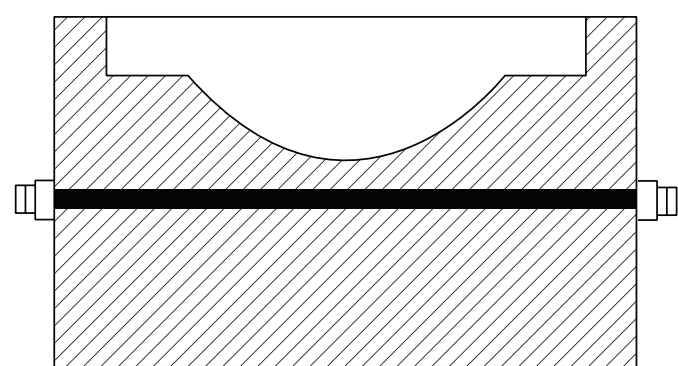

(a)

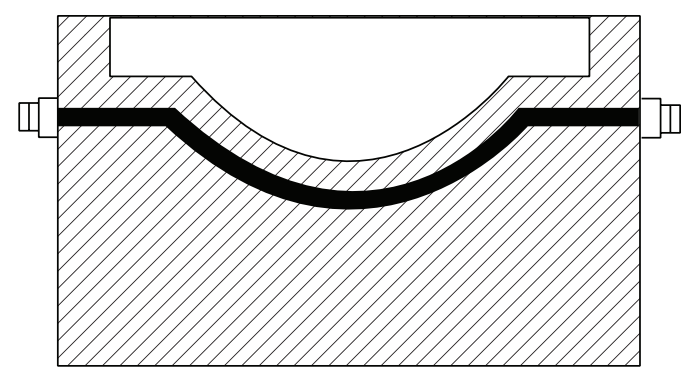

(b)

FIgURE 1: (a) Straight drilled cooling channel. (b) Conformal cooling channel.

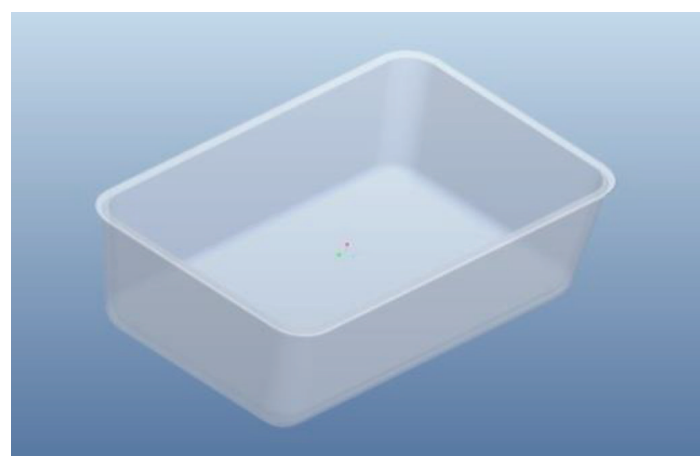

Figure 2: CAD model of food container.

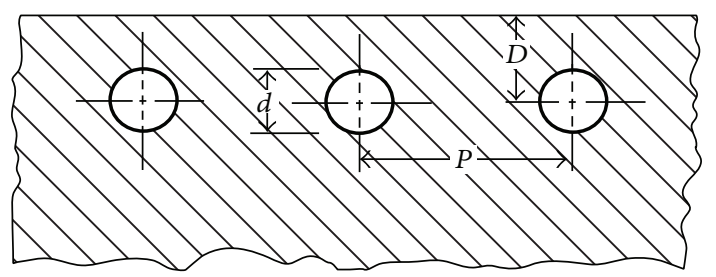

Recommended depth and pitch

$d=$ diameter of water line $=7 / 16$ to $9 / 16$ inch

$D=$ depth of water line $=d$ to $2 d$

$P=$ pitch $=3 d$ to $5 d$

FIGURE 3: Layout of cooling channels in injection mold.

the cooling channel "conforms" to the shape of the cavity in the molds (Figure 1).

Research in conformal cooling system has mainly focused on simulation studies and testing of prototype conformal cooling molds using various techniques [5]. KonsulovaBakalova has used thermal simulation software, SolidWorks Simulation, and compared conformal cooling channels with circular and elliptical cross-sections. He has concluded that the cooling time of part has been optimized by using conformal cooling channels and results translate a reduction in production cycle time and increase in the quality of the parts [6]. Researchers have designed an automatic method for designing conformal cooling circuit. First they formulated a relationship between the conformal cooling and the geometrical shape of cooling circuit. Based on that, they investigated a geometric modeling algorithm to design the cooling circuit approaching the conformal cooling. Simulations have been taken to verify the advantage of the cooling circuit generated by their algorithm [7]. It is verified by numerical and experimental investigation that threedimensional thickness control method (3DTCM) is helpful to manage the warpage of the injected parts. With special gate design, material selection, and various operation conditions, warpage of injected parts can be managed significantly [8].

In this study the time to reach ejection temperature, time to reach part ejection temperature (freezing time), shrinkage, and temperature variance have been studied for four different cooling channels.

\section{Part Design and Cooling Channel Design}

In this case study, a plastic food container has been modeled using Creo Elements/Pro 5.0 (Figure 2). Part is $145 \mathrm{~mm}$ in length, $94 \mathrm{~mm}$ in width, $1.5 \mathrm{~mm}$ in thickness, and $50 \mathrm{~mm}$ in height. The sat (Standard ASCI Text) model file of the plastic part has been imported to Autodesk Mold Flow Advisor 2013 (AMFA) to perform mold flow analysis.

The appropriate location for cooling channels is inside the mold cavity or core with proper distance apart from the mold surface and between the successive cooling channels. Figure 3 shows that the distance $(D)$, from cavity surface to the center of cooling channel, should be one to two times of cooling channel diameter $(d)$. The pitch of cooling channels should lie between $3 d$ to $5 d$ whereas a typical channel's diameter ranges from 10 to $14 \mathrm{~mm}$ [9]. The design rule is that " $D$ " should be $1 \times d$ for Steel, $1.5 \times d$ for Beryllium, and $2 \times d$ for Aluminum [1].

As the proposed mold material is Tool Steel P-20, the selected cooling channel diameter is $10 \mathrm{~mm}$. Layouts of cooling channel analyzed in this study are the conventional cooling channel design, conformal cooling channels connected in series, conformal cooling channels connected in parallel, and conformal cooling channels with additive cooling lines (Figure 4).

In conventional cooling channel (CCC) straight drilled cooling lines are used (Figure 4(a)). In the second design, series conformal cooling channels (SCC), cooling channels conform to the shape of the part and they are connected in series with each other (Figure 4(b)) whereas, in 


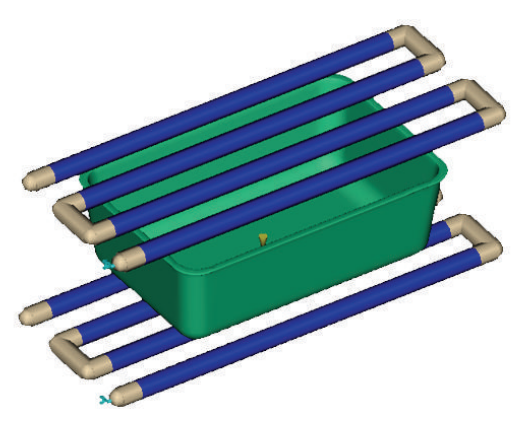

(a)

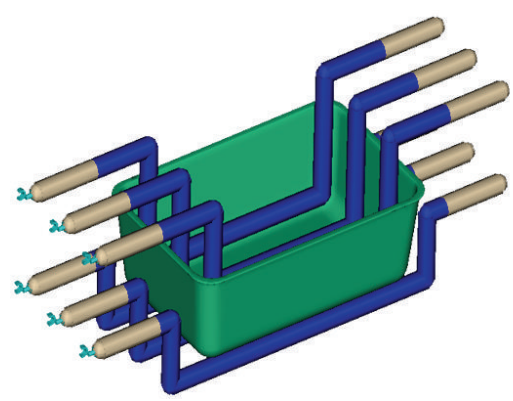

(c)

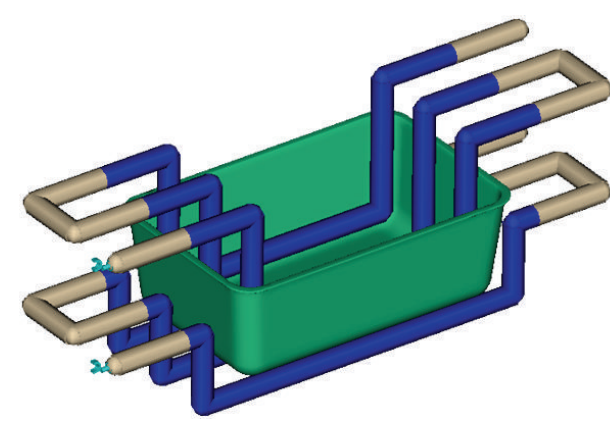

(b)

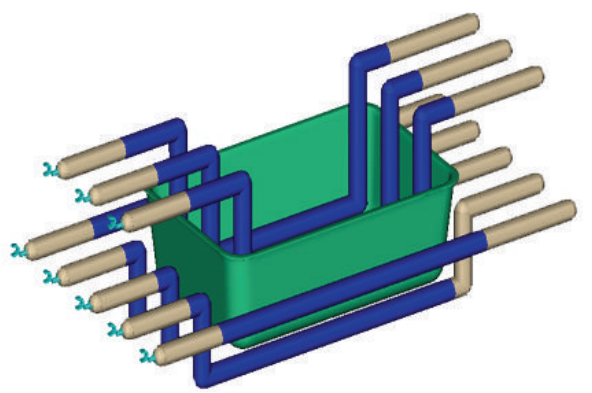

(d)

Figure 4: (a) Conventional cooling channel design. (b) Series conformal cooling design. (c) Parallel conformal cooling channel. (d) Conformal cooling channel with additive cooling lines.

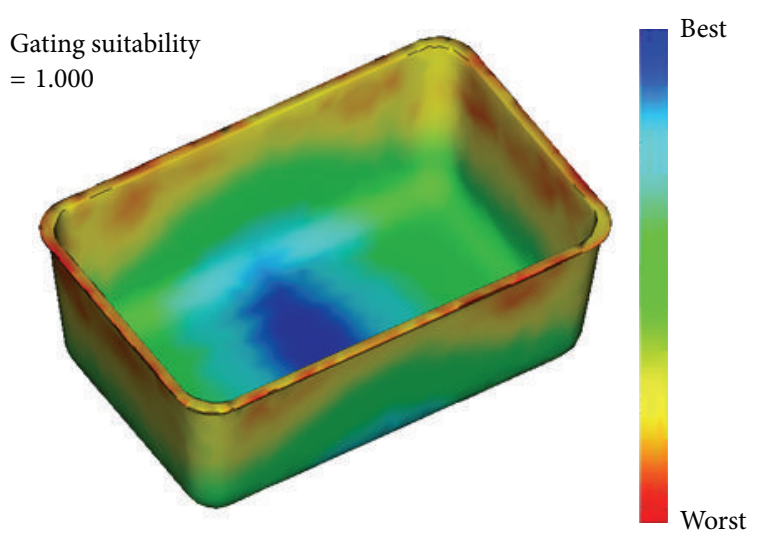

Scale $(100 \mathrm{~mm})$

the third design, parallel conformal cooling channels (PCC), the same conformal cooling channels are connected in parallel (Figure 4(c)). In the last channel design, conformal cooling channel with additive cooling lines (CCAL), along with conformal cooling lines, two straight cooling channels are also placed on both sides of the part (Figure $4(\mathrm{~d})$ ).

\section{Mold Flow Analysis}

The mold flow analysis is performed after assigning Polypropylene (PP) Purell HM671T material to the plastic

Melt temperature $=225.0^{\circ} \mathrm{C}$

Purell HM671T: Basell polyolefins

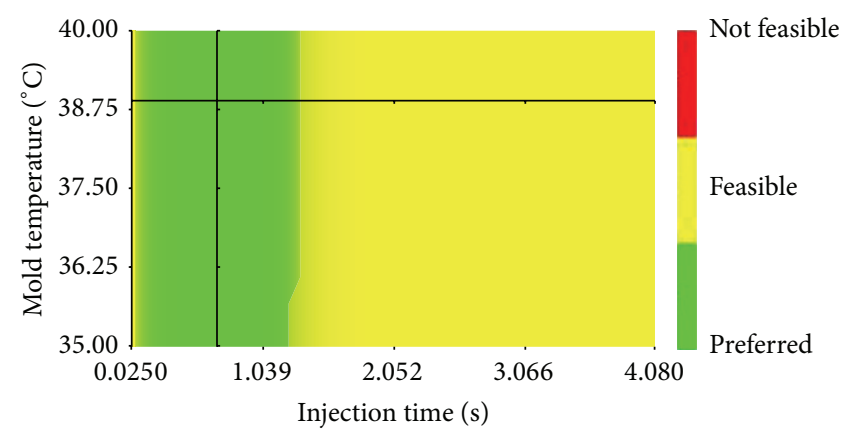

FIGURE 6: Molding windows.

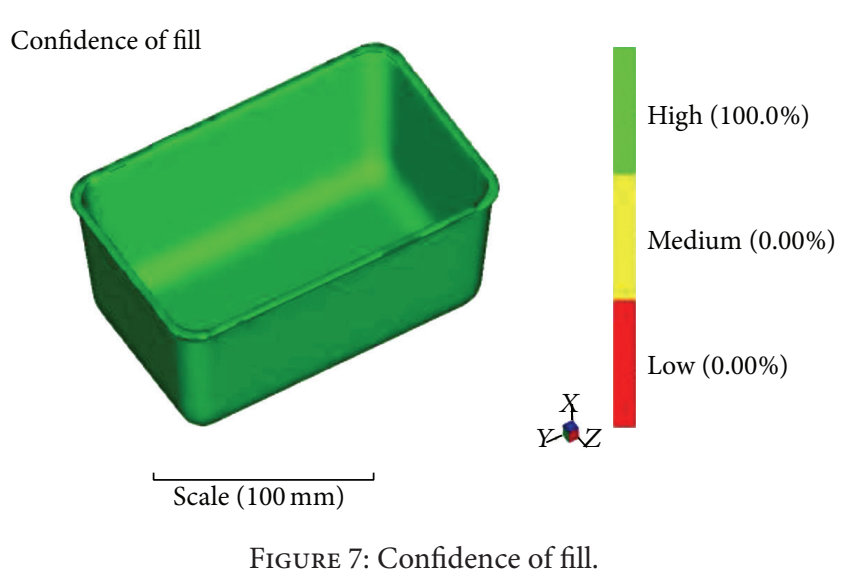




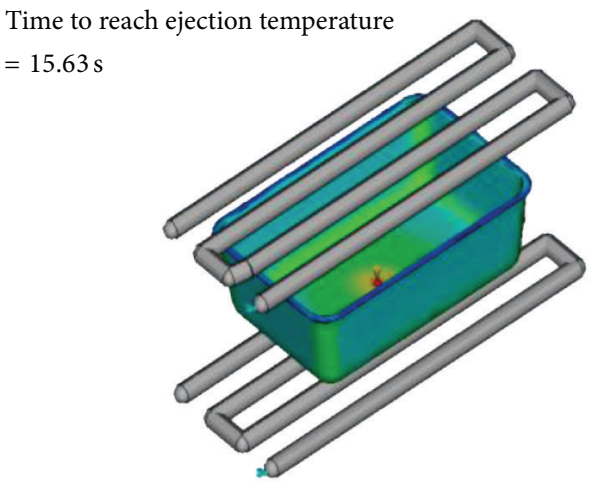

(a)

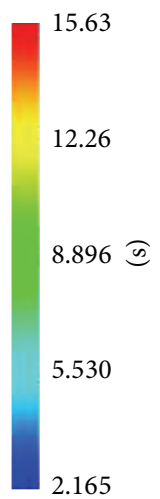

2.165
Time to reach ejection temperature

$=14.63 \mathrm{~s}$

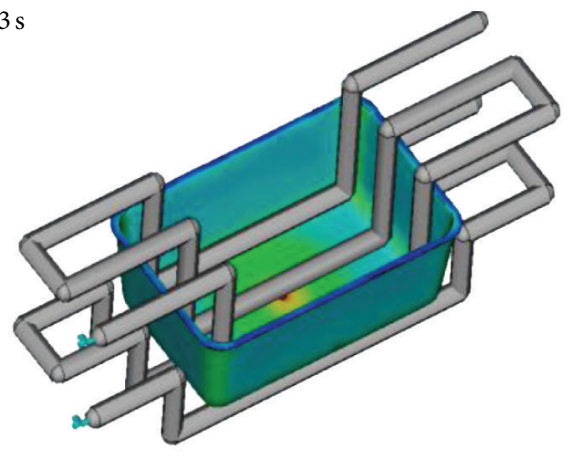

(b)

FIGURE 8: Time to reach ejection temperature with (a) conventional cooling channel and (b) series conformal cooling channels.

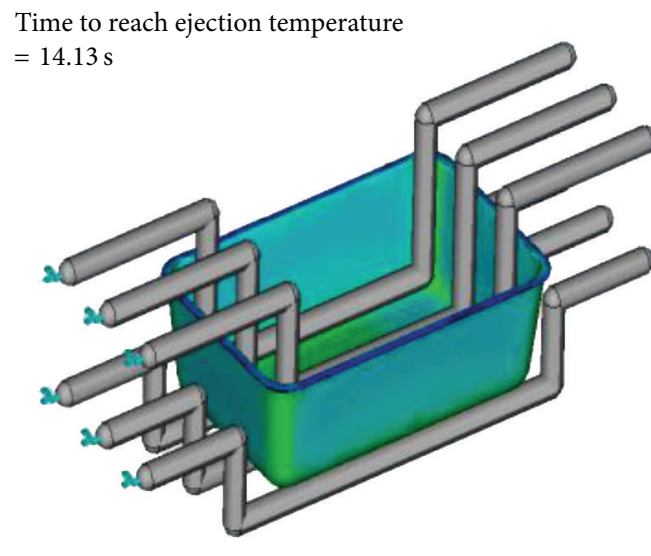

(a)

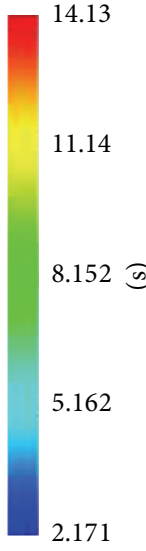

2.171

FIGURE 9: Time to reach ejection temperature with (a) parallel conformal cooling channels and (b) conformal cooling channels with additive lines.

TABLE 1: Thermal and mechanical properties.

\begin{tabular}{lcc}
\hline Number & Property & Value \\
\hline 1 & Density $\left(\mathrm{g} / \mathrm{cm}^{3}\right)$ & 0.9 \\
2 & Melt temperature $\left({ }^{\circ} \mathrm{C}\right)$ & 168 \\
3 & Thermal conductivity $\left(10^{-4} \mathrm{cal} / \mathrm{sec} \mathrm{cm}^{\circ} \mathrm{C}\right)$ & 2.8 \\
4 & Heat capacity $\left(\mathrm{cal} / \mathrm{g}^{\circ} \mathrm{C}\right)$ & 0.9 \\
\hline
\end{tabular}

part. The part weight for this material is 43.17 grams, excluding sprue and gating system. The thermal and mechanical properties of PP are shown in Table 1 [1].

On AMFA first of all "gate location analysis" is performed and results show that the best location is on the base of the part (Figure 5).

In the second step "molding windows" analysis is performed to evaluate the optimum material conditions required for part production. The purpose of molding windows is to improve manufacturability of the part. Molding windows of the case study for Polypropylene Purell HM671T material is shown in Figure 6 . The injection time is shown on $x$-axis whereas $y$-axis shows melt temperature. The molding windows is divided into three areas, which are green (preferred), yellow (feasible), and red (not feasible). Figure 6 shows that our selected zone is in the preferred region (green area); thus it will lead to a high part quality. At the optimum point in the molding window, the melt temperature is $225^{\circ} \mathrm{C}$ and mold temperature is $38.89^{\circ} \mathrm{C}$ whereas the injection time is 0.6912 seconds.

Using these optimal conditions Fill + Pack + Warp + Cooling quality analysis is performed. Dual domain meshing is used and the number of nodes and triangles in the mesh is 9225 and 18446, respectively. Figure 7 shows the "confidence of fill" for the case study and it is clear that part has high $(100 \%)$ confidence of fill at the optimum point of molding windows.

Then at the end "cool" analysis is performed for each cooling channel design. The cooling fluid is pure water with inlet temperature $25^{\circ} \mathrm{C}$ and at $4 \mathrm{lit} / \mathrm{min}$ volume flow rate. The coolant Reynolds number is 9401.5 which indicates that flow of water is fully turbulent because the flow in a round pipe is turbulent if the Reynolds number is greater than 
Time to reach ejection temperature, part $=5.536 \mathrm{~s}$

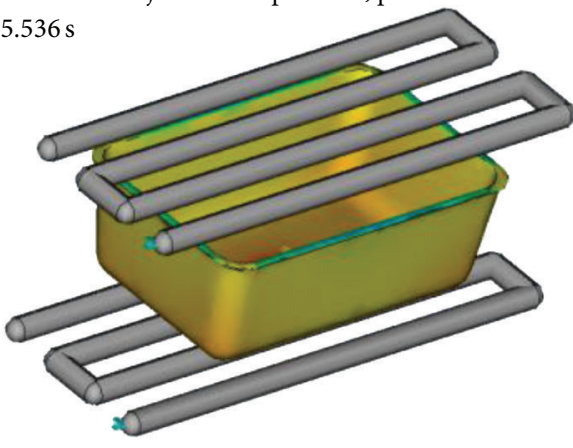

(a)

Time to reach ejection temperature, part $=5.113 \mathrm{~s}$

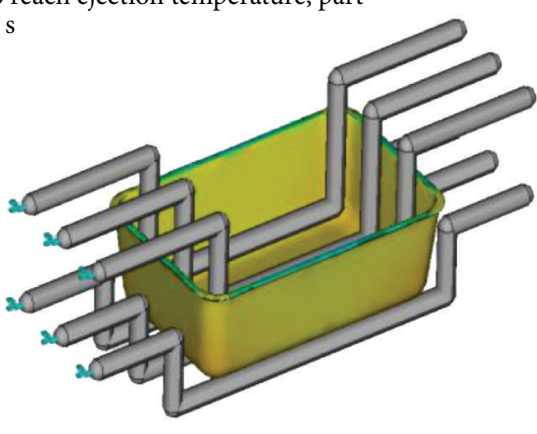

(c)

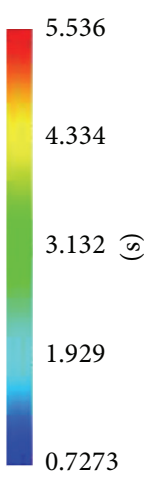

0.7273

5.113

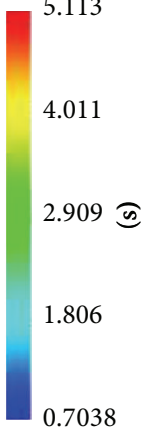

0.7038

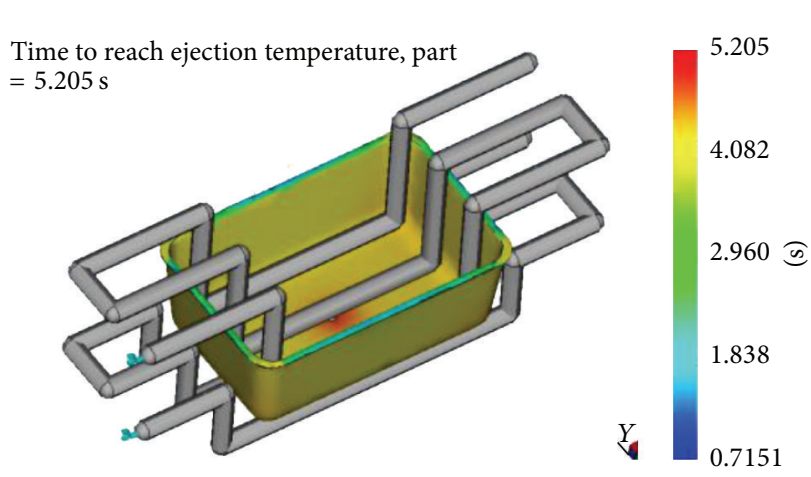

(b)

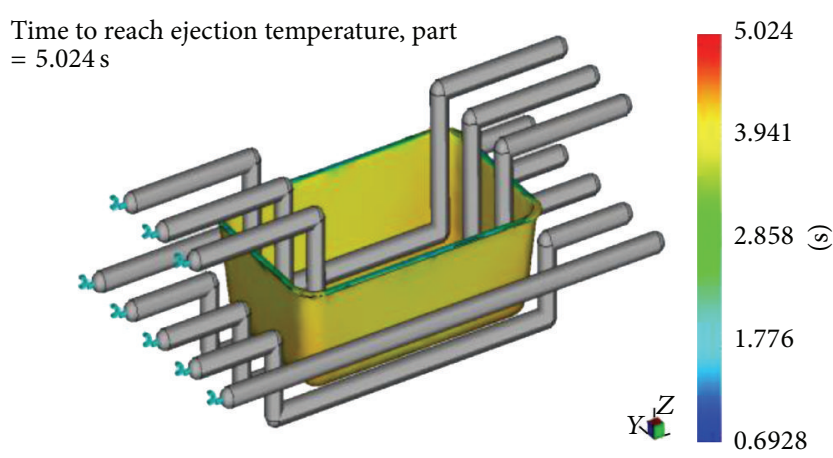

(d)

FIGURE 10: Time to reach part ejection temperature with (a) conventional cooling channels, (b) series conformal cooling channels, (c) parallel conformal cooling channels, and (d) conformal cooling channels with additive lines.

TABLE 2: Summary of Fill + Pack + Cool analysis results.

\begin{tabular}{lccccc}
\hline Number & $\begin{array}{c}\text { Cooling } \\
\text { channel }\end{array}$ & $\begin{array}{c}\text { Time to reach ejection } \\
\text { temperature } \\
\text { seconds }\end{array}$ & $\begin{array}{c}\text { Time to reach part ejection } \\
\text { temperature } \\
\text { seconds }\end{array}$ & $\begin{array}{c}\text { Volumetric } \\
\text { shrinkage } \\
\%\end{array}$ & $\begin{array}{c}\text { Temperature } \\
\text { variance } \\
{ }^{\circ} \mathrm{C}\end{array}$ \\
\hline 1 & CCC & 15.63 & 5.664 & 11.39 & 9.723 \\
2 & SCC & 14.63 & 5.205 & 9.89 & 6.436 \\
3 & PCC & 14.13 & 5.113 & 8.498 & 5.693 \\
4 & CCAL & 14.13 & 5.024 & 8.477 & 5.297 \\
\hline
\end{tabular}

approximately 4000 [10]. The turbulent flow is very important because it provides an additional mechanism for momentum and heat transfer [11]. Cooling channels have a uniform diameter $(d)$ of $10 \mathrm{~mm}$ and they are placed at a depth of $10 \mathrm{~mm}$ $(1 \times d)$ from part surface.

\section{Results and Discussions}

The simulation results in terms of time to reach ejection temperature (time required to reach the ejection temperature, which is measured from the start of fill), time to reach part ejection temperature (time required by the part to freeze), volumetric shrinkage at ejection, and the temperature variance of the part are discussed here. These results show that conventional cooling channels take 15.63 seconds to reach ejection temperature for the case study part as shown by red color in Figure 8(a).

However, time required to reach ejection temperature decreased to 14.63 seconds by use of conformal cooling channel connected in series. This shows that using same pitch and the cooling channel diameter conformal cooling channels connected in series provides $6.39 \%$ faster cooling as compared to the conventional cooling channels (Figure 8(b)).

The simulation results show that both parallel conformal cooling channel and conformal cooling channel with additive cooling lines take 14.13 seconds to reach ejection temperature. Thus these combinations are $9.5 \%$ faster as compared to the conventional cooling channels (Figure 9). These results show that the conventional cooling channel combination is the slowest cooling system because it requires more time than other systems. These CCC are basically straight drilled holes that have some limitations in terms of geometric complexity 


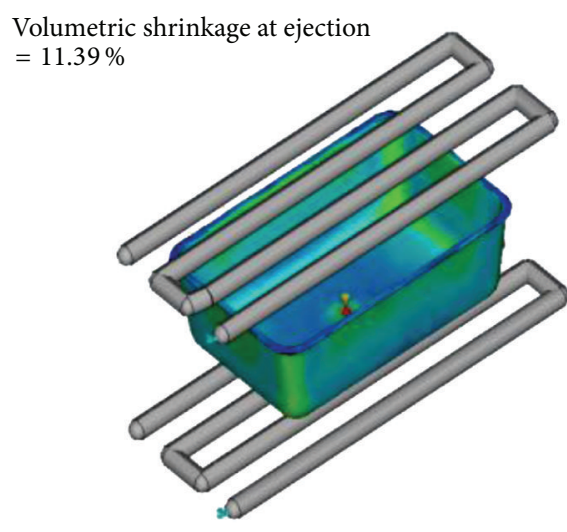

(a)

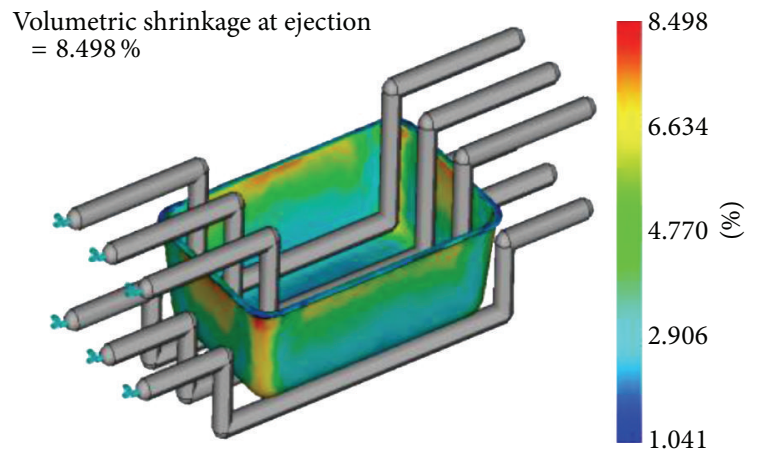

(c)

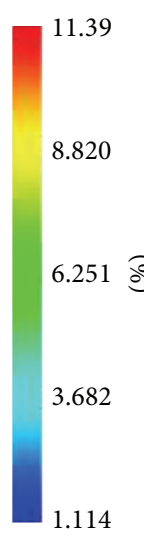

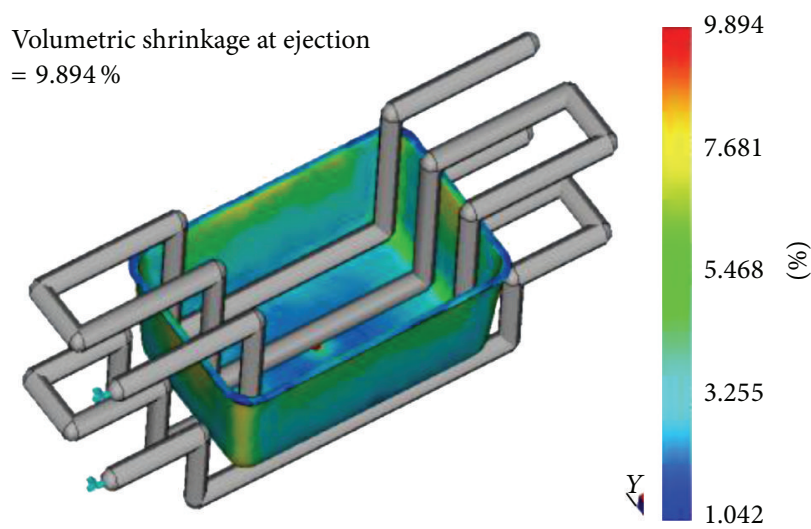

(b)

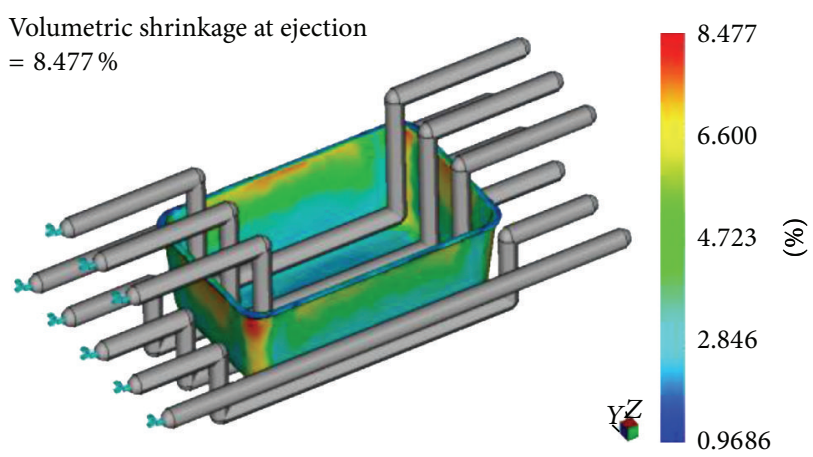

(d)

FIGURE 11: Percentage volumetric shrinkage at ejection with (a) conventional cooling channels, (b) series conformal cooling channels, (c) parallel conformal cooling channels, and (d) conformal cooling channels with additive lines.

and nonuniform cooling between the surfaces of the part and cooling fluid mobility within the injection mold [12], whereas PCC and CCAL are faster combinations.

Similarly, when the results of time to reach part ejection temperature are studied, the CCC takes 5.664 seconds, SCC takes 5.205 seconds, PCC takes 5.113 seconds, and the CCAL takes 5.024 seconds. This shows that the CCC consumes maximum time and CCAL takes minimum time to reach part ejection temperature. The results also show that SCC, PCC, and CCAL are $8.1 \%, 9.7 \%$, and $11.29 \%$ faster, respectively, as compared to the CCC. Thus CCAL is the fastest cooling channel combination as compared to others (Figure 10).

The next parameter of comparing these cooling channels is percentage of "volumetric shrinkage at ejection." This parameter gives information about the percentage reduction in volume of the part with respect to the original part at the time of ejection. The lesser the value of the volumetric shrinkage is, the higher the part accuracy will be. The simulations results show that CCC shows $11.39 \%$, SCC shows 9.89\%, PCC shows 8.498 , and CCAL shows $8.477 \%$ shrinkage (Figure 11).

The results show that CCC shows maximum shrinkage whereas SCC, PCC, and CCAL show 13.16\%, 25.39\%, and $25.57 \%$ less shrinkage as compared to the CCC, respectively. Thus CCAL shows minimum shrinkage among other cooling channel combinations.
The last parameter of comparison in this study is "temperature variance" among different regions of the part with respect to the average ejection temperature of the part. This temperature is responsible for the warpage of the part. If the mold temperature is not equal on two mold walls, this leads to thermokinetic asymmetry of melt flow. This, in turn, causes the asymmetrical structure development in the part crosssection. As a result, different stresses in part's cross-section occur, which result in part warpage [13]. In this case study the ejection temperature of the part is $38^{\circ} \mathrm{C}$. The temperature variation simulations show that the variation of temperature in CCC is $9.723^{\circ} \mathrm{C}$, whereas SCC, PCC, and CCAL show $6.436^{\circ} \mathrm{C}, 5.693^{\circ} \mathrm{C}$, and $5.297^{\circ} \mathrm{C}$ temperature variation, respectively (Figure 12). Thus, as usual CCC has maximum temperature variation whereas CCAL has minimum. So CCAL will have minimum part warpage.

Figure 13 shows a comparison of "time to reach ejection temperature" and "time to reach part ejection temperature" of these cooling channel configurations as shown in Figure 14. Figure 15 shows comparison of "volumetric shrinkage at ejection" and "temperature variation" of part due to these cooling channel configurations as shown in Figure 16.

Table 2 summarizes the results obtained from Autodesk Moldflow Advisor 2013.

On the basis of comparison of the results shown in Table 2 and Figures 13, 14, 15, and 16 it can be concluded 


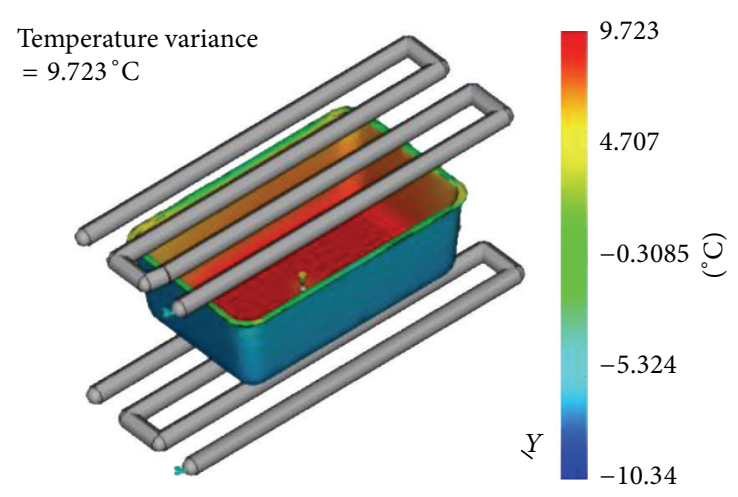

(a)

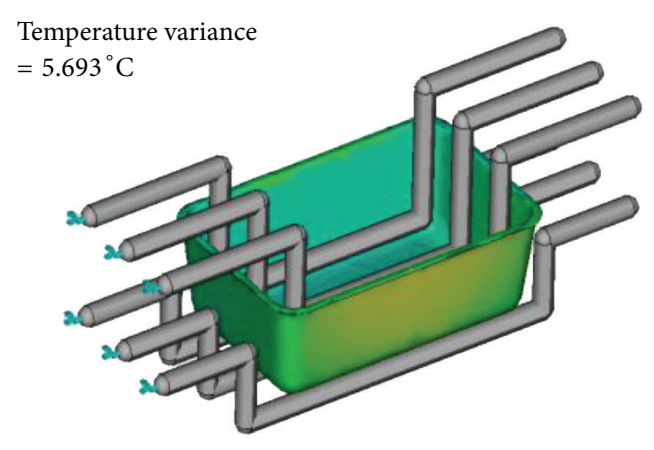

(c)

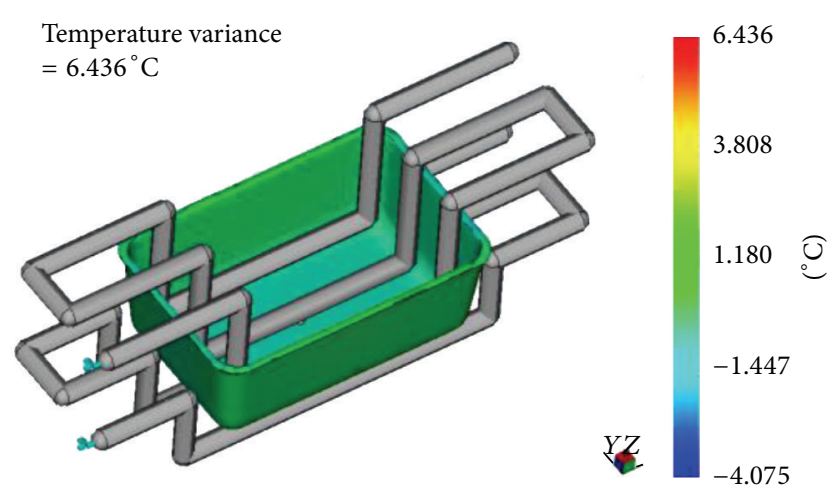

(b)
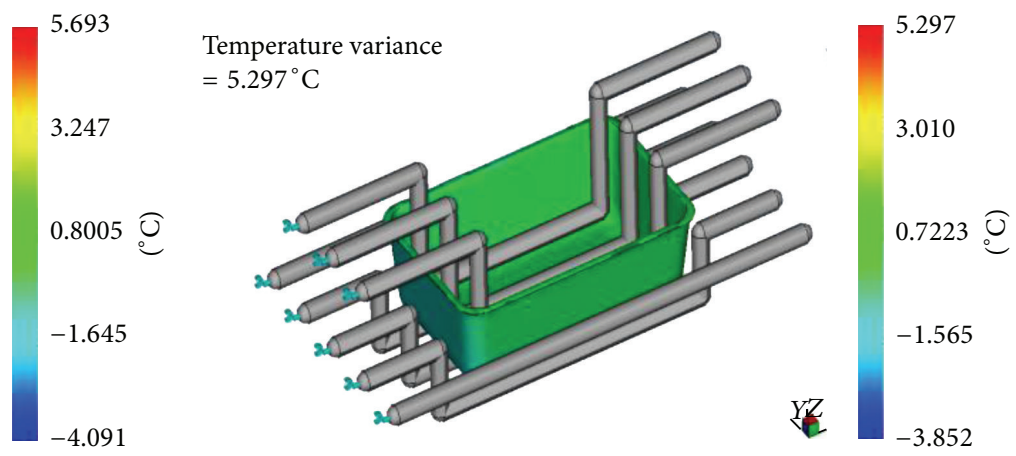

(d)

FIGURE 12: Temperature variation in part with (a) conventional cooling channel, (b) series conformal cooling channels, (c) parallel conformal cooling channels, and (d) conformal cooling channels with additive lines.

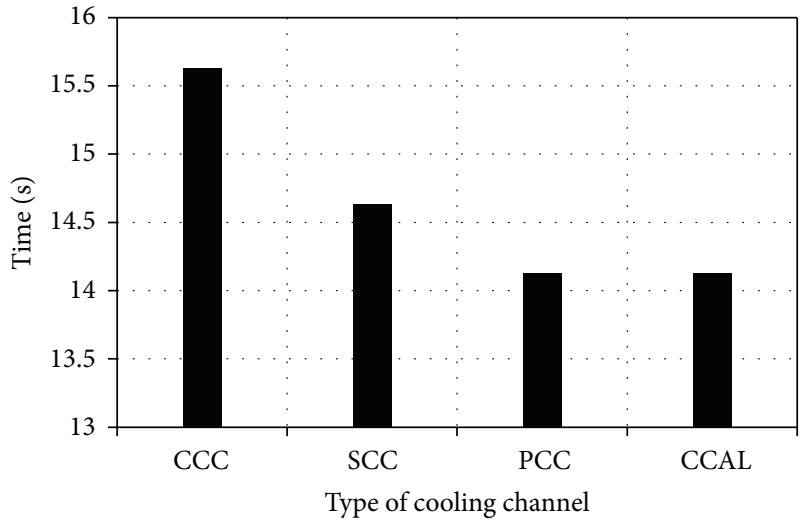

FIgURE 13: Comparison of time to reach ejection temperature.

that "conformal cooling channels with additive cooling lines" are the most efficient and suitable cooling system for the case study part among other cooling channels. It has lower time to reach ejection temperature, lower time to reach part ejection temperature, lower volumetric shrinkage, and lower temperature variance; thus it will lead to a better part quality with minimum cycle time. As the temperature variation is also minimum in CCAL, there will be minimum warpage of the part that translates to a better part quality as compared to the CCC, SCC, and PCC because of more uniform cooling in CCAL.

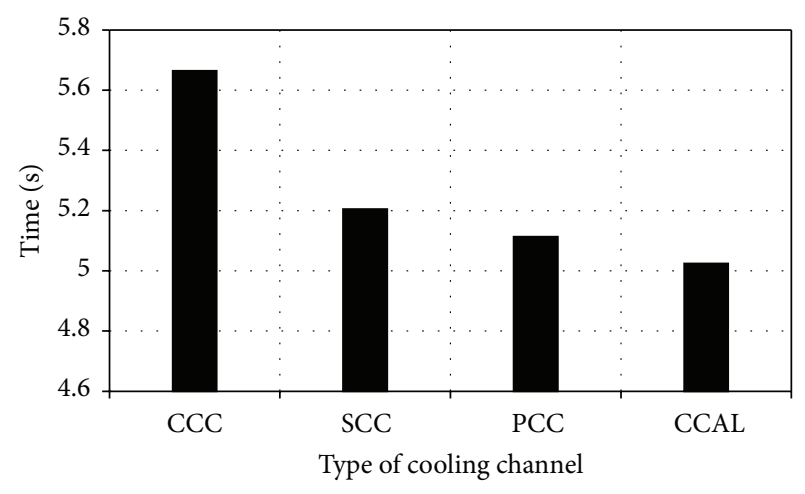

FIgURE 14: Comparison of time to part ejection temperature.

\section{Conclusion}

In this case study, four different types of cooling channel layouts are studied named as "conventional cooling channels" (CCC), "series conformal cooling channels" (SCC), "parallel conformal cooling channels" (PCC), and "conformal cooling channels with additive cooling lines" (CCAL) for cooling of a food container. Simulations for filling, packing, and cooling of molded part are performed on Autodesk Mold Flow Advisor. From simulation results it is being concluded that although the conformal cooling lines provide better 


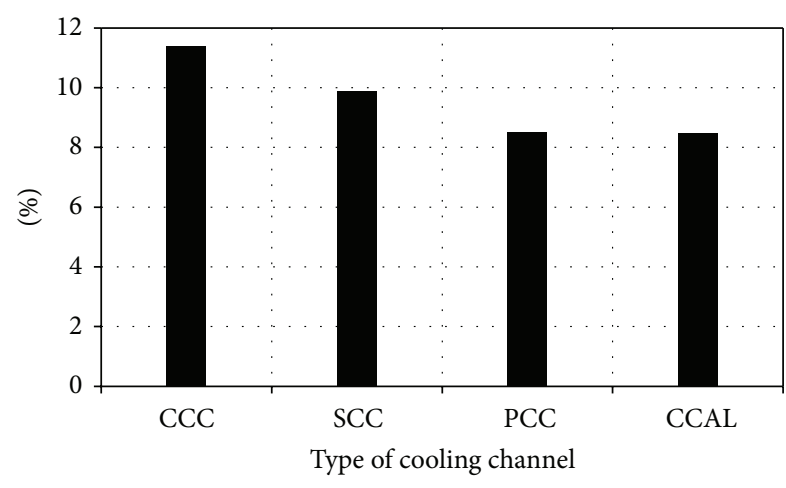

FIGURE 15: Comparison of volumetric shrinkage at part ejection.

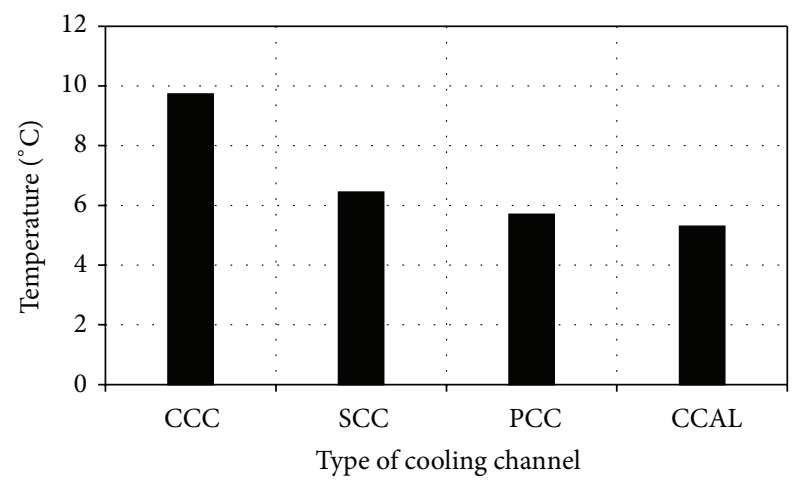

FIgURE 16: Comparison of part temperature variance.

cooling as compared to conventional cooling lines, yet using the additive cooling lines with conformal cooling channels provides even more uniform cooling and takes less cooling time because not only these conform to the geometry of the part but also the additive lines improve the cooling.

It is also very important to ensure uniform cooling of molded part in the injection mold (especially in case of complex parts) by proper cooling system design. It can be done with the help of CAE simulation software like Autodesk Mold Flow Advisor.

\section{Conflict of Interests}

The authors declare that there is no conflict of interests regarding the publication of this paper.

\section{Acknowledgments}

This research work is a part of "Design and Fabrication of Energy Efficient Injection Molding Machine" sponsored by Pakistan Science Foundation (letter no.: PSF/Res/Invenandinnov/P-HITEC/2013). The authors of this research work are thankful to Dr. Syed Touseef Mohi-udDin Mr. Nizar Ullah Khan, Mr. Adeel Akhtar Shah, and Mr. Luqman Ahmad Nizam for their technical support and guidance.

\section{References}

[1] D. V. Rosato and M. G. Rosato, Injection Molding Handbook, Springer, 2000.

[2] S. H. Masood and N. N. Trang, "Thermal analysis of conformal cooling channels in injection moulding," in Proceedings of the 3rd BSME-ASME International Conference on Thermal Engineering, Dhaka, Bangladesh, 2006.

[3] J. Shoemaker, Moldflow Design Guide: A Resource for plastics Engineers, vol. 10, Hanser Publishers, 2006.

[4] J. Meckley and R. Edwards, "A Study on the design and effectiveness of conformal cooling channels in rapid tooling inserts," The Technology Interface Journal, vol. 10, no. 1, 2009.

[5] A. Saifullah, S. Masood, and I. Sbarski, "New cooling channel design for injection moulding," in Proceedings of the World Congress on Engineering, 2009.

[6] "Application ofsolidwoks simulation for design of cooling system for injection molding," International Virtual Journal. In press.

[7] Y. Wang, K.-M. Yu, C. C. L. Wang, and Y. Zhang, "Automatic design of conformal cooling circuits for rapid tooling," $C A D$ Computer Aided Design, vol. 43, no. 8, pp. 1001-1010, 2011.

[8] Y. Chang, S. T. Huang, S.-W. Huang et al., "Warpage management using three dimensional thickness control method in injection molding," in Proceedings of the 67th Annual Technical Conference of the Society of Plastics Engineers (ANTEC '09), pp. 2429-2435, June 2009.

[9] K. M. Au, ConFormal Cooling Channels Design for Rapid Plastic Injection Mould, 2009.

[10] B. R. Munson, D. F. Young, and T. H. Okiishi, Fundamentals of Fluid Mechanics, John Wiley and Sons, 4th edition, 2010.

[11] Y. A. Cengel, Heat and Mass Transfer: A practical Approach, Tata McGraw-Hill Education, 2007.

[12] J. P. Beaumont, R. Nagel, and R. Sherman, Successful Injection Molding, Hanser Publishers, 2002.

[13] E. Bociaga, T. Jaruga, K. Lubczyńska, and A. Gnatowski, "Warpage of injection moulded parts as the result of mould temperature difference," Archives of Materials Science and Engineering, vol. 44, no. 1, pp. 28-34, 2010. 

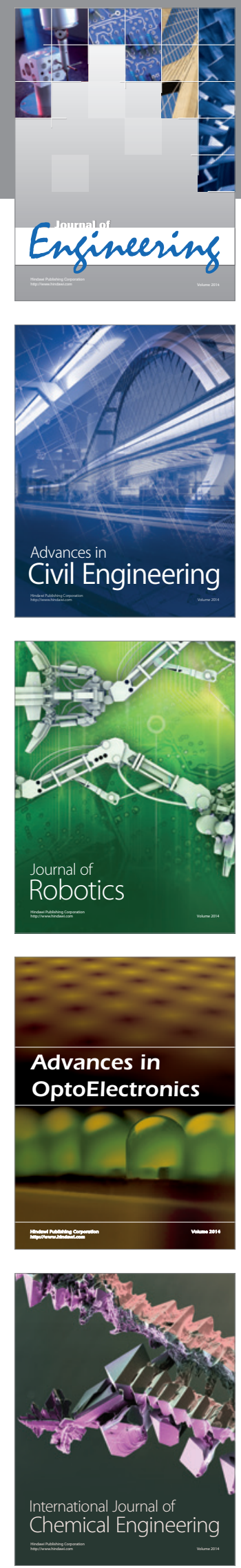

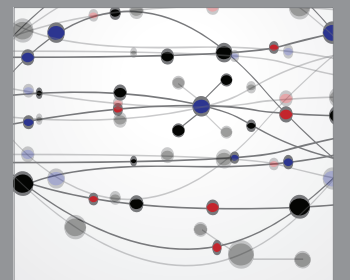

The Scientific World Journal
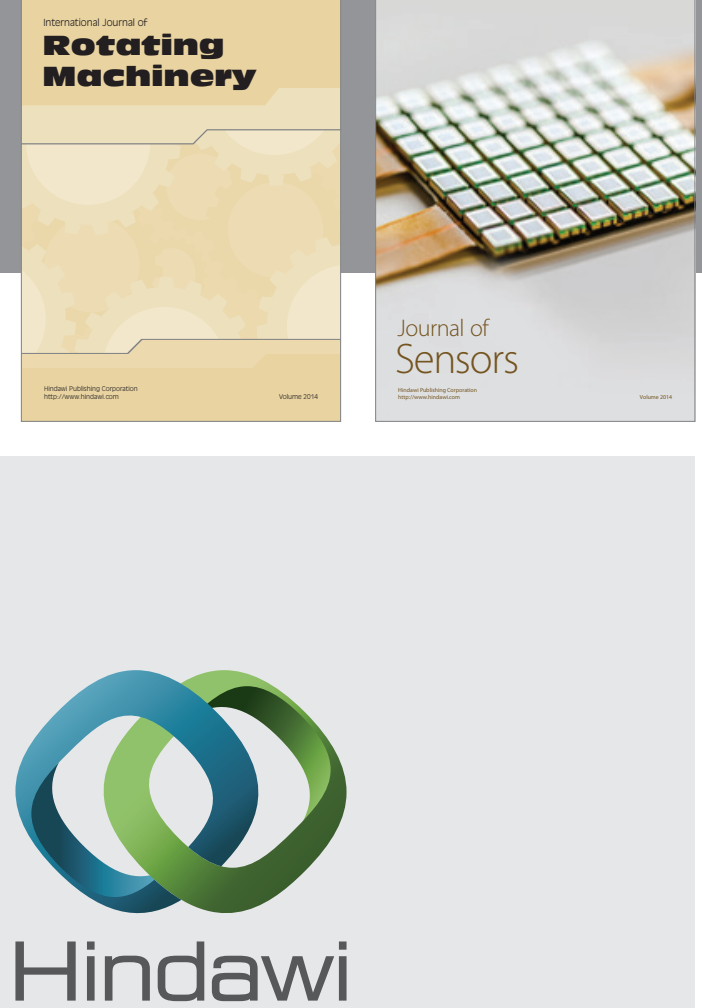

Submit your manuscripts at http://www.hindawi.com
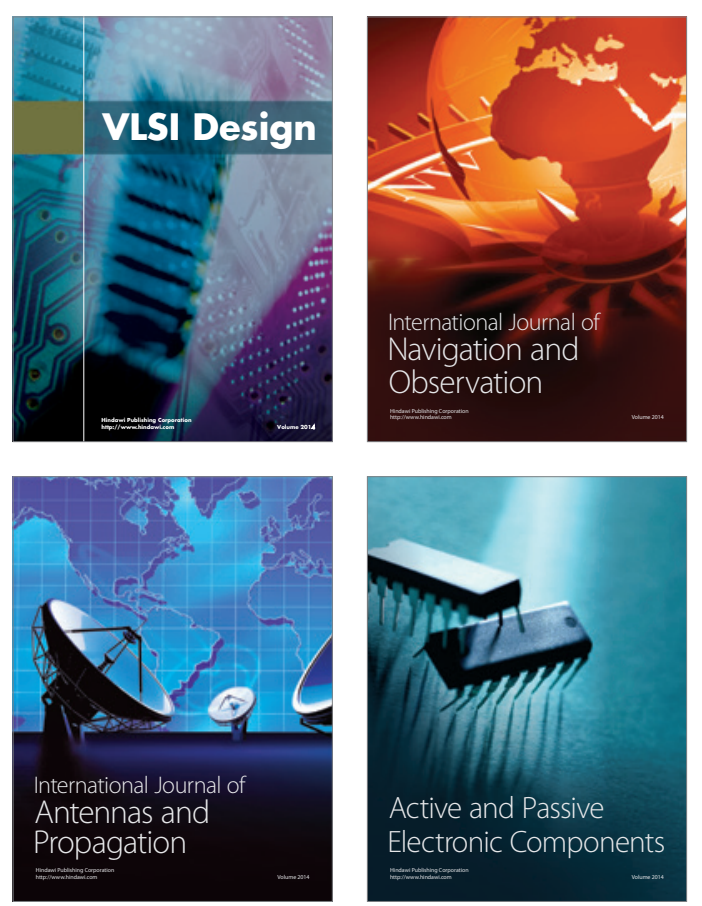
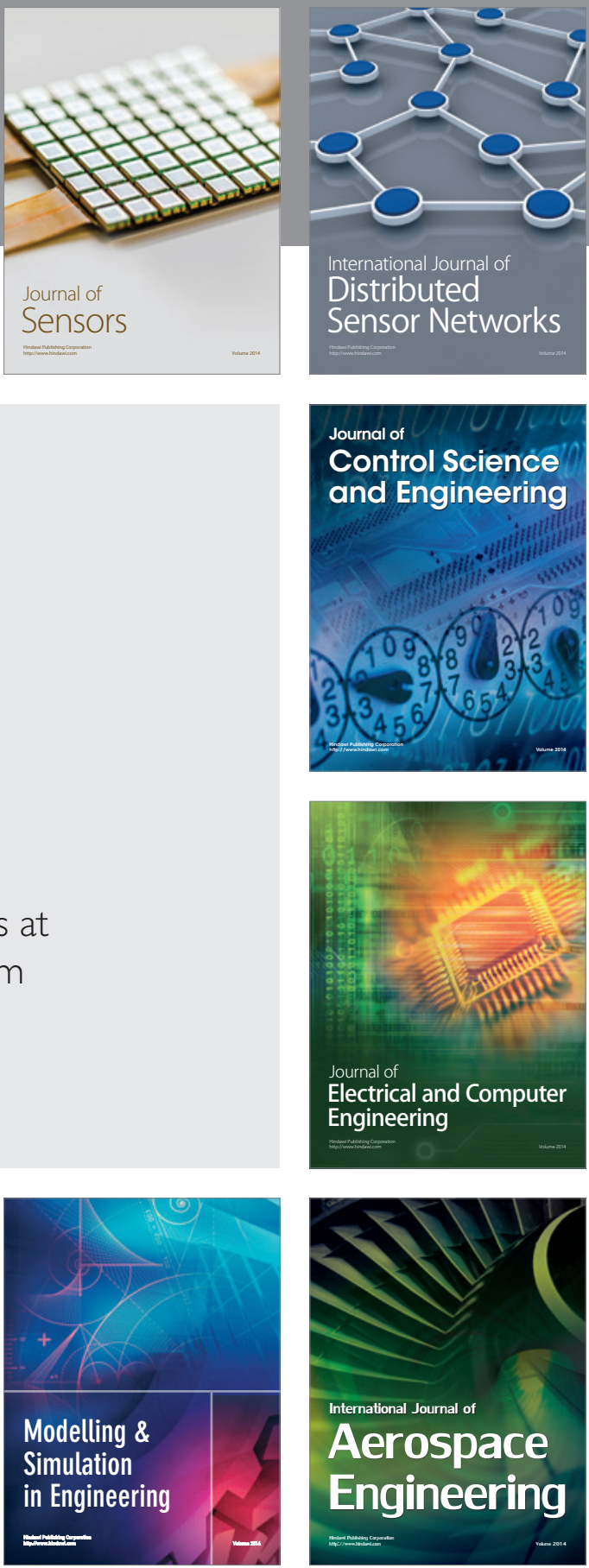

Journal of

Control Science

and Engineering
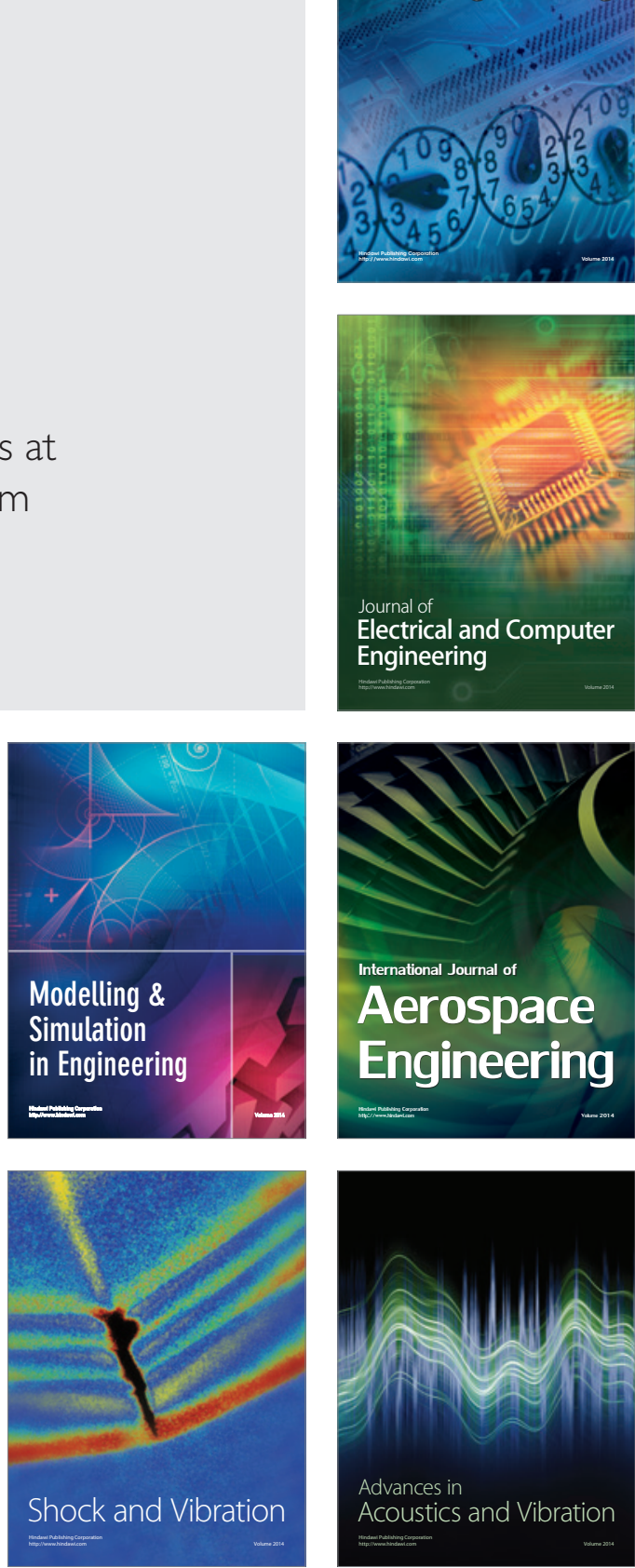